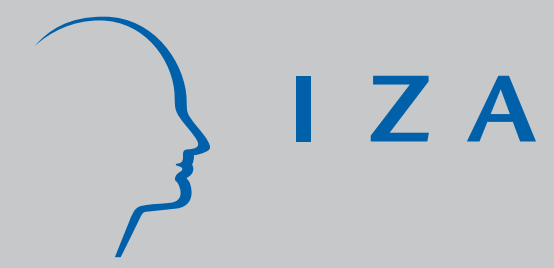

IZA DP No. 265

\title{
Structurally Dependent Competing Risks
}

Michael Rosholm

Michael Svarer

February 2001 


\title{
Structurally Dependent Competing Risks
}

\author{
Michael Rosholm \\ University of Aarhus, CLS, CIM and IZA, Bonn \\ Michael Svarer \\ University of Aarhus, CLS and CIM \\ Discussion Paper No. 265 \\ February 2001 \\ IZA \\ P.O. Box 7240 \\ D-53072 Bonn \\ Germany \\ Tel.: +49-228-3894-0 \\ Fax: +49-228-3894-210 \\ Email: iza@iza.org
}

This Discussion Paper is issued within the framework of IZA's research area Mobility and Flexibility of Labor Markets. Any opinions expressed here are those of the author(s) and not those of the institute. Research disseminated by IZA may include views on policy, but the institute itself takes no institutional policy positions.

The Institute for the Study of Labor (IZA) in Bonn is a local and virtual international research center and a place of communication between science, politics and business. IZA is an independent, nonprofit limited liability company (Gesellschaft mit beschränkter Haftung) supported by the Deutsche Post AG. The center is associated with the University of Bonn and offers a stimulating research environment through its research networks, research support, and visitors and doctoral programs. IZA engages in (i) original and internationally competitive research in all fields of labor economics, (ii) development of policy concepts, and (iii) dissemination of research results and concepts to the interested public. The current research program deals with (1) mobility and flexibility of labor markets, (2) internationalization of labor markets and European integration, (3) the welfare state and labor markets, (4) labor markets in transition, (5) the future of work, (6) project evaluation and (7) general labor economics.

IZA Discussion Papers often represent preliminary work and are circulated to encourage discussion. Citation of such a paper should account for its provisional character. 
IZA Discussion Paper No. 265

February 2001

\section{ABSTRACT}

\section{Structurally Dependent Competing Risks}

In this paper, we specify and estimate a structurally dependent competing risks model for the transitions out of unemployment into either new job or recall. The recall probability is allowed to affect the search intensity for new jobs.

JEL Classification: C41, J64

Keywords: Competing risks, structural dependence, recall hazard, new job hazard

Michael Rosholm

Dept. of Economics

University of Aarhus

Building 350

DK-8000 Aarhus C

Denmark

Tel.: +4589421559

Fax: +45861363 34

Email: mrosholm@econ.au.dk

\footnotetext{
* Financial Support from the Danish Social Science Research Council is gratefully acknowledged. We are also grateful to Anne Møller Jensen and seminar participants at the econometric seminar series at the University of Aarhus for useful comments.
} 


\section{Introduction}

In this paper we specify and estimate a simultaneous equations model for hazards. The model proves useful in applications where the processes describing different dynamic situations are structurally dependent. Our particular example considers the process for unemployment durations. We consider unemployed workers searching for jobs. Job offers are assumed to arrive from either the previous employer (recall) or from a new employer. Recalls may carry a higher wage due to accumulation of firm-specific human capital. This implies that the intensity of search for new jobs will be inversely related to the recall probability ${ }^{1}$. Hence the term structural dependence.

The paper contributes to two different branches of the literature. First, the application adds a new dimension to the distinction between recall versus new job transitions out of unemployment. Katz (1986) estimated the two transitions in a competing risks model assuming that the two hazards are independent, conditional on some observed variables. Han \& Hausman (1990) extended the analysis by allowing for dependence between the recall hazard and the new job hazard through correlation between unobserved variables. In this paper we extend the Han \& Hausman model by incorporating structural dependence between the hazard rates. We do this by including the recall hazard as an additional explanatory variable in the new job hazard.

Second, the model provides an alternative specification of a simultaneous hazard model, compared to the models developed by Lillard (1993) or Fallick \& Ryu (1997).

\footnotetext{
${ }^{1}$ See Fallick \& Ryu (1997) for a theoretical model that implies this relationship between the recall hazard and the new job hazard.
} 
Lillard's model assumes that the unobserved variables are jointly normally distributed, and he obtains identification of the structural dependence parameter by exclusion restrictions on the covariates. Fallick \& Ryu rely on identification by functional form nonlinearities. In our model, we show that identification may be obtained without exclusion restrictions, and without resorting to functional form assumptions, when repeated spells are available.

The paper is organized as follows. Section 2 presents the econometric model, and in Section 3 we describe the data. Section 4 contains the results, and in Section 5 we conclude.

\section{Econometric Model}

The econometric model is a competing risks hazard model ${ }^{2}$. Each of the destination specific hazards is specified as a mixed proportional (sub-) hazard. The destination specific hazard for recall is

$$
h_{r}\left(t \mid x, v_{r}\right)=\lambda_{r}(t) \exp \left(\beta_{r}^{\prime} x+v_{r}\right) .
$$

where $x$ is observed and $v_{r}$ is unobserved. The destination specific hazard rate for new job is specified in the following way

$$
h_{n}\left(t \mid x, \varepsilon_{n}\right)=\lambda_{n}(t) \exp \left(\beta_{n}^{\prime} x+v_{n}+\alpha h_{r}\left(t \mid x, v_{r}\right)\right)
$$

Note, that the parameter $\alpha$ captures the structural dependence of the new job hazard rate on the recall probability. Fallick \& Ryu (1997) only included the recall baseline

\footnotetext{
${ }^{2}$ See Lancaster (1990) for more on hazard models.
} 
hazard $\left(\lambda_{r}(t)\right)$ in the new job hazard (thus leaving out the individual specific part of the recall hazard). This implies that, in their case, identification was obtained through functional form assumptions. They found strong effects in the patterns of duration dependence from introducing the structural element into the model. However, since there is no variation in the recall baseline hazard between persons, their specification amounts to being a highly nonlinear respecification of the new job baseline hazard rate, that is, instead of $\lambda_{n}(t)$, the new job baseline becomes $\lambda_{n}(t) \cdot \exp \left(\alpha \lambda_{r}(t)\right)$. Lillard (1993), on the other hand, included the entire recall hazard in the new job hazard and relied on exclusion restrictions for identification. ${ }^{3}$

In our case, there are various sources of variation providing identification. The parameters of the recall hazard is identified from data on recalls alone. The parameters of the new job hazard are identified, and $\alpha$ is identified through three sources of variation, namely variation in the recall hazard rate over time (the baseline), variation in the level of the recall hazard between individuals (observed and unobserved variables), and variation in the recall hazard within individuals across spells (observed variables), as an individual may be observed in more than one spell of unemployment (see section 3).

In deriving the likelihood function, we first specify some distributional assumptions and introduce some notation: Assume that the baseline hazards are piecewise constant with splitting times $\tau_{0}, \tau_{1}, \ldots, \tau_{K}$, with $\tau_{0}=0, \tau_{K}=+\infty$. Let the values of the baseline hazard rates in the k'th interval be given by $\lambda_{r}^{k}, \lambda_{n}^{k}$. Define the mapping

\footnotetext{
${ }^{3}$ The principle of exclusion restrictions is well suited for Lillard's application (joint distribution of the duration of marriage and timing of marital conception), but not for Fallick \& Ryu's or ours.
} 
$k(t): \Re_{+} \curvearrowright\{1,2, \ldots, K-1, K\}$, which maps a duration, $t$, into an interval, $k$. Finally, the destination state $J=n, r$ gives two destination indicators, $d_{n}=\mathbb{I}_{\{J=n\}}, d_{r}=\mathbb{I}_{\{J=r\}}$. The likelihood contribution for a single unemployment spell, conditional on observed and unobserved variables, may now be expressed as

$\mathcal{L}(\theta)=h_{r}\left(t \mid x, v_{r}\right)^{d_{r}} \cdot h_{n}\left(t \mid x, v_{n}, v_{r}\right)^{d_{n}} \cdot \exp \left[-\int_{0}^{t} h_{r}\left(s \mid x, v_{r}\right) d s-\int_{0}^{t} h_{n}\left(s \mid x, v_{n}, v_{r}\right) d s\right]$

The unobserved variables are assumed to be individual specific (that is, the random effect is assumed to be constant across different spells for the same individual), and to follow a discrete distribution with $2 \times 2$ points of support. Since there is already a constant (i.e. the baseline hazard) in each of the destination specific hazards, we make the normalization that one of the support point in each destination specific hazard takes the value zero.

\section{Data}

The data is a flow sample of all unemployment spells initiated by a $0.2 \%$ sample of the Danish population during the period Jan. 1, 1981 to Dec. 31, 1990. The data is extracted from registers used for UI-benefit payments. For each unemployment spell, the duration of the spell and the subsequent destination (recall, new job, or something else) is known. If the spell does not end before Dec. 31, 1990, it is treated as independent right censoring. The same holds for transitions out of the labour force.

For the purpose of the present analysis, we select men in the age group 25-59. The 
sample contains 1422 individuals with at least one fresh unemployment spell during the period, and a total of 7781 fresh unemployment spells (5.5 spells on average per person), of which 3950 end with a transition into a new job, and 3016 end with a recall.

A number of explanatory variables are used in the estimations; Age, actual working experience, educational level, demographic and geographic variables as well as UI-fund membership indicators. Their coefficients are, however, not reported below, due to limitations of space.

\section{Estimation Results}

The parameter estimates for the coefficients of the model are shown in Table 1. In Model A we estimate the model without introducing structural dependence (that is, the traditional competing risks model), whereas in Model B, we have allowed for structural dependence in the manner of Fallick and Ryu, by including the recall baseline as an explanatory variable in the new job hazard. ${ }^{4}$ Finally, Model $\mathrm{C}$ presents the estimation results for the specification presented above.

\footnotetext{
${ }^{4}$ Model B still differs of that by Fallick and Ryu in that we exploit the availability of repeated spells to identify the unobservables' distribution.
} 
TABle 1: Estimation Results (Asymptotic standard errors in italics)

\begin{tabular}{|c|c|c|c|c|c|c|}
\hline \multirow[b]{2}{*}{$v_{2, r}$} & \multicolumn{2}{|c|}{ Model A } & \multicolumn{2}{|c|}{ Model B } & \multicolumn{2}{|c|}{ Model C } \\
\hline & 1.6968 & 0.0491 & 1.7673 & 0.0542 & 1.7179 & 0.0381 \\
\hline$v_{2, n}$ & 1.2112 & 0.0471 & 1.2156 & 0.0479 & 1.2879 & 0.0448 \\
\hline $\operatorname{Pr}\left(v_{1, r}, v_{1, n}\right)$ & 0.4901 & 0.0283 & 0.4649 & 0.0275 & 0.5522 & 0.0229 \\
\hline $\operatorname{Pr}\left(v_{1, r}, v_{2, n}\right)$ & 0.2847 & 0.0222 & 0.3171 & 0.0239 & 0.2579 & 0.0234 \\
\hline $\operatorname{Pr}\left(v_{2, r}, v_{1, n}\right)$ & 0.1694 & 0.0247 & 0.1505 & 0.0230 & 0.1001 & 0.0156 \\
\hline $\operatorname{Pr}\left(v_{2, r}, v_{2, n}\right)$ & 0.0558 & 0.0158 & 0.0675 & 0.0177 & 0.0898 & 0.0181 \\
\hline$\alpha$ & & & 0.0996 & 1.0284 & -2.8604 & 0.4867 \\
\hline $\operatorname{Corr}\left(v_{r}, v_{n}\right)$ & -0.1055 & 0.0571 & -0.0815 & 0.0589 & 0.1271 & 0.0674 \\
\hline $\log \mathcal{L}$ & $-26,063$ & & $-26,061$ & & $-26,052$ & \\
\hline
\end{tabular}

The (unreported) effect from the covariates on the three hazard rates are not strongly affected by the inclusion of the recall hazard in the new job hazard. ${ }^{5}$

The distribution of the unobserved heterogeneity terms is quite similar between the three specifications. There is, nevertheless one important difference. If we calculate the correlation of $v_{r}, v_{n}$, it is negative in Models $\mathrm{A}$ and $\mathrm{B}$, albeit only significantly so in Model A. A negative correlation implies that individuals who, based on the unobserved components, are more prone to leave unemployment through recall, are less prone to leave unemployment for a new job. This result appears counter-intuitive. In Model C, the correlation is significantly positive, and the negative correlation of Model A (and B) is thus a consequence of neglecting the structural dependency that exists between the two hazards.

In Model B we find that the coefficient of structural dependence, $\alpha$, is very poorly determined due to the reliance on functional form identification only. In Model C we find a significant negative coefficient of structural dependence, which confirms the prediction that the intensity devoted to search for a new job declines in the recall probability. Our

\footnotetext{
${ }^{5}$ Full estimation results are available on request.
} 
Model $\mathrm{C}$ does thus in all respects live up to our a priori expectations, in contrast with the Models A and B. In addition, the improvement of the likelihood function in going from either $\mathrm{A}$ or $\mathrm{B}$ to $\mathrm{C}$ is large.

In Figure 1 we depict the hazard functions. The recall hazard still exhibits negative duration dependence as expected, and the inclusion of the structural dependency does not alter the baseline profiles, except for a small change in the new job hazard, corresponding to the effect from the time-varying recall probability.

\section{Conclusion}

In this paper we specify and estimate a simultaneous equations model for hazards. Our particular example considers the process for unemployment durations, where the unemployed workers can leave unemployment for a job at their previous employer (recall) or for a job with a new employer. We argue that there is a structural dependency between the destination states, since individuals would prefer to return to their previous employer, and consequently the intensity devoted to search for a new job declines in the recall probability.

Our extension of the standard competing risks model appears fruitful since we find significantly different results when including the structural dependency. Specifically, we confirm the theoretical prediction that the recall hazard affects the new job hazard negatively, and that this phenomenon, if not accounted for by the statistical model, affects the correlation structure of the unobserved heterogeneity components. Our model 
thus outperforms the standard competing risks model and the extension suggested by Fallick and Ryu (1997).

\section{References}

[1] Fallick, B.F. and K. Ryu (1997). "Structural Duration Analysis of Lay-off Unemployment Spell: Recall vs. New Job", Draft.

[2] Han, A. and J.A. Hausman (1990). "Flexible Parametric Estimation of Duration and Competing Risk Models", Journal of Applied Econometrics, 5, 1-28.

[3] Katz, L. F. (1986). "Layoffs, Recall and the Duration of Unemployment", NBER Working Paper No. 1825.

[4] Lancaster, T. (1990). The Econometric Analysis of Transition Data, Cambridge University Press.

[5] Lillard, L.A. (1993). "Simultaneous Equations for Hazards - Marriage Duration and Fertility Timing", Journal of Econometrics, 56, 189-217. 


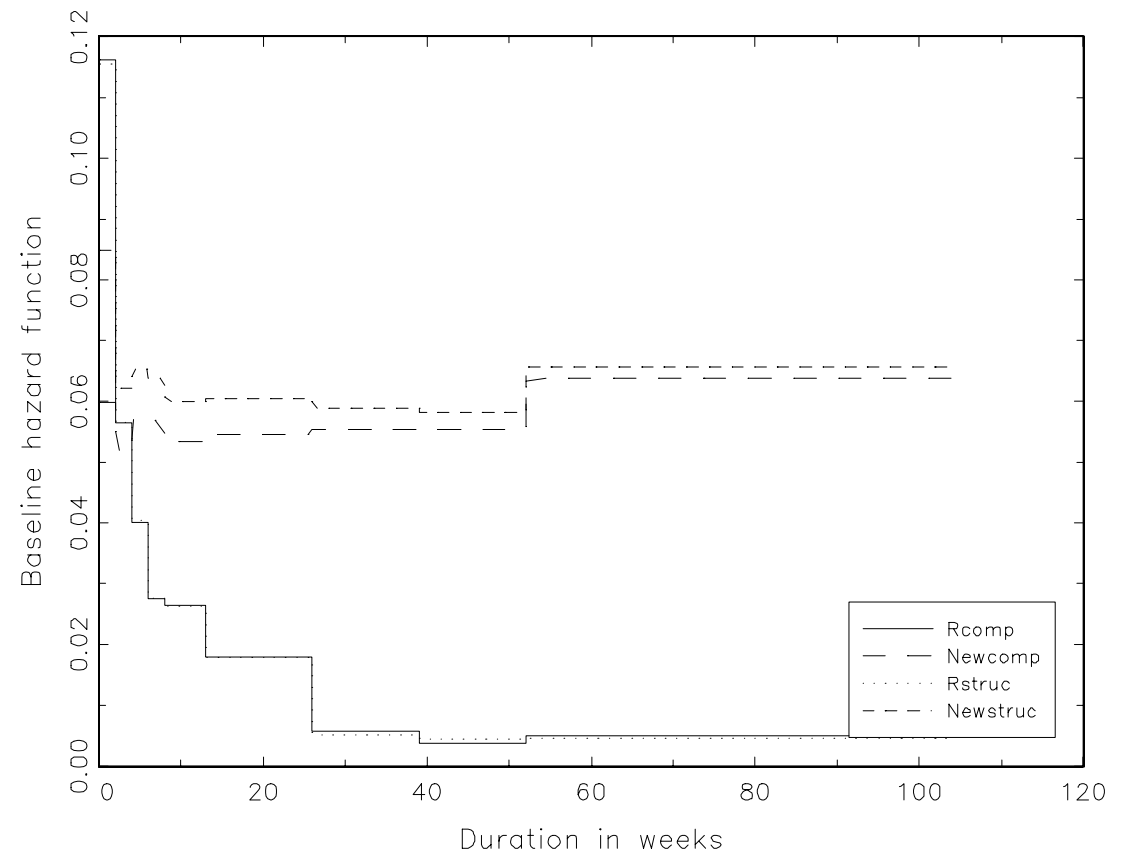

Figure 1: Baseline hazard function for Model A and Model C.

Note: Rcomp is the average baseline recall hazard for Model A, Rstruc is the average baseline recall hazard for Model C, Newcomp is the average new job baseline hazard for Model A, while Newstruc is the average new job baseline hazard for Model C. 


\section{IZA Discussion Papers}

\section{No Author(s)}

181

E. Wasmer

Y. Zenou

182 M. Fertig

C. M. Schmidt

183 M. Fertig

C. M. Schmidt

184 M. Corak

B. Gustafsson

T. Österberg

185 H. Bonin

K. F. Zimmermann

186

C. Dustmann

187
T. K. Bauer
M. Lofstrom
K. F. Zimmermann

188
A. Kapteyn
A. S. Kalwij
A. Zaidi

189

W. Arulampalam

190

C. Dustmann

I. Preston

191

192

G. C. Giannelli

C. Monfardini

193 A. Kunze

F. Pastore

G. Brunello

F. Büchel

A. Mertens

Titel

Area

Date

Space, Search and Efficiency

2

$8 / 00$

Discretionary Measures of Active Labor Market Policy: The German Employment Promotion Reform in Perspective

Aggregate-Level Migration Studies as a Tool for 1 Forecasting Future Migration Streams

Intergenerational Influences on the Receipt of 3 Unemployment Insurance in Canada and Sweden

The Post-Unification German Labor Market

4

$8 / 00$

Temporary Migration and Economic Assimilation

$8 / 00$

Immigration Policy, Assimilation of Immigrants and Natives' Sentiments towards Immigrants: Evidence from 12 OECD-Countries

The Myth of Worksharing

5

$8 / 00$

Is Unemployment Really Scarring? Effects of

3

$8 / 00$

Unemployment Experiences on Wages

Racial and Economic Factors in Attitudes to

Immigration

$8 / 00$

Joint Decisions on Household Membership and Human Capital Accumulation of Youths: The role of expected earnings and local markets

$8 / 00$

Absolute Risk Aversion and the Returns to

5

$8 / 00$ Education

The Determination of Wages and the Gender Wage Gap: A Survey

Restructuring in Poland

Overeducation, Undereducation, and the Theory of Career Mobility 
198 M. Kreyenfeld

A Forgotten Issue: Distributional Effects of Day 
212 X. Gong

A. van Soest

P. Zhang

213 X. Gong

A. van Soest

E. Villagomez

214 X. Gong

A. van Soest

215 J. Ermisch

M. Francesconi

216 F. Büchel

217

J. Hansen

R. Wahlberg

218 C. Dustmann

A. van Soest

219 F. Kramarz

T. Philippon

220 W. A. Cornelius

E. A. Marcelli

221

C. Grund

222 W.P.M. Vijverberg

223 M. Rosholm

M. Svarer

J. Schwarze

225

L. Modesto

J. P. Thomas
Sexual Bias and Household Consumption: A

Mobility in the Urban Labor Market: A Panel Data 1

The Effect of Parents' Employment on Children's

The Effects of Overeducation on Productivity in Variables

The Impact of Differential Payroll Tax Subsidies on 5 Minimum Wage Employment United States: New Evidence from California and Mexico

Wages as Risk Compensation in Germany 

former Soviet Union to Israel: Who is coming when?

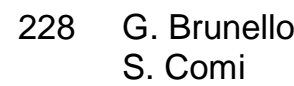

C. Lucifora

229 R. Coimbra

T. Lloyd-Braga

L. Modesto

230 L. Modesto

231

G. Saint-Paul

232

E. Bardasi

M. Francesconi

233

C. Dustmann

C. M. Schmidt

234

R. Rotte

M. Steininger

235

W. Schnedler

236
R. Hujer
M. Caliendo

237 S. Klasen

I. Woolard

238 R. Euwals

A. Börsch-Supan

A. Eymann

239 F. Andersson

K. A. Konrad

240

W. Koeniger
The College Wage Gap in 10 European and Earnings: An Empirical Study for Portugal Wahlerfolge in Deutschland: Das Beispiel der Europawahlen 1994 und 1999

Who gets the Reward? An Empirical Exploration of Bonus Pay and Task Characteristics

Evaluation of Active Labour Market Policy: 

Soviet Union: A Study of the Suicide Epidemic in the 1990s

244 S. M. Fuess, Jr. M. Millea

T. J. Hatton

J. G. Williamson

251

R. Yemtsov

252

R. Yemtsov

254 H. Gersbach

A. Schniewind

255 H. Gersbach

A. Schniewind

T. Boeri

H. Brücker

Pay and Productivity in a Corporatist Economy: 
258 M. Rosholm

The Times They Are A-Changin':

K. Scott

Organizational Change and Immigrant

L. Husted

Employment Opportunities in Scandinavia

259 A. Ferrer-i-Carbonell

Poverty in the Russian Federation

4

02/01

B. M.S. van Praag

260

P. Cahuc

Temporary Jobs, Employment Protection and

$1 / 3$

$02 / 01$

F. Postel-Vinay

Labor Market Performance

261 M. Lindahl

Home versus School Learning:

5

$02 / 01$

A New Approach to Estimating the Effect of Class

Size on Achievement

262 M. Lindahl

Summer Learning and the Effect of Schooling:

5

$02 / 01$

Evidence from Sweden

263 N. Datta Gupta

Children and Career Interruptions:

5

$02 / 01$

N. Smith

The Family Gap in Denmark

264

C. Dustmann

Return Migration, Wage Differentials, and the Optimal Migration Duration

$02 / 01$

265 M. Rosholm

Structurally Dependent Competing Risks

1

$02 / 01$ 